\title{
Effect of Curcumin on Beta-Amyloid Plasma Level in Alzheimer Disease: A Systematic Review and Meta-analysis
}

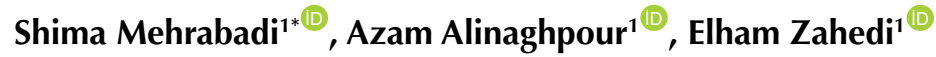 \\ ${ }^{1}$ Department of Physiology, School of Medicine, Tehran University of Medical Sciences, Tehran, Iran
}

\begin{abstract}
Alzheimer's disease is known as a most common dementia disorder in the world. The famous hypothesis about the cause of this disease is beta-amyloid $(A \beta)$ accumulation in the brain. There is a widespread neuroinflammation in the patient's brain, leading to neuronal apoptosis and brain atrophy. Curcumin is a well-known anti-inflammation and anti-oxidant ingredient. It can easily cross the blood-brain barrier. There are controversial results about the effects of curcumin on $A \beta$ clearance and metabolism in Alzheimer's disease and the elderly. The aim of this meta-analysis and systematic review was to review the effect of curcumin on $A \beta$ clearance in clinical studies. We performed a systematic review and meta-analysis on the three randomized clinical trials (RCTs) and one pilot study that assessed the effect of curcumin on A $\beta$ plasma level in Alzheimer's disease. For this purpose, we searched PubMed and Scopus databases up to December 2020. Our result showed there was no significant change in serum $A \beta$ level (weighted mean difference [WMD]: $5.3,95 \% \mathrm{Cl}$ : 0.78-9.97) following curcumin consumption in patients with Alzheimer's disease. Further clinical trials should be done to evaluate the effects of curcumin in A $\beta$ level in Alzheimer's disease.

Keywords: Alzheimer's disease, Beta-amyloid, Curcumin, Meta-analysis
\end{abstract}

*Correspondence to Shima Mehrabadi, Department of Physiology, School of Medicine, Tehran University of Medical Sciences, Tehran, Iran Tel/Fax: +982166419484; Email: shimamehrabadi@ yahoo.com

Published online March 27, 2021

Citation: Mehrabadi S, Alinaghpour A, Zahedi E. Effect of curcumin on beta-amyloid plasma level in alzheimer disease: a systematic review and meta-analysis. Clin Neurosci J. 2021;8(2):55-59. doi:10.34172/icnj.2021.13.

\section{Introduction}

Alzheimer's disease is a common neurodegenerative disease worldwide. ${ }^{1,2}$ The most important cause mentioned was the accumulation of beta-amyloid $(\mathrm{A} \beta)$ fibril in the central nervous system (CNS). ${ }^{3}$ Actually disruption in $\mathrm{A} \beta$ homeostasis can lead to the accumulation of $\mathrm{A} \beta$ fibrils as plaques in the brain. ${ }^{4,5}$ These plaques can be detected by microglia receptors and finally activate signal cascades into microglia that lead to the release of inflammatory factors from microglia. ${ }^{6,7}$ So, in brain of patients with Alzheimer's disease, there is a widespread neuroinflammation that can lead to neuronal apoptosis and brain atrophy. ${ }^{8}$ The deposition of $\mathrm{A} \beta$ protein is a prominent pathological hallmark of brains affected by Alzheimer's disease. For this reason, the inhibition of $A \beta$ production, prevention of $\mathrm{A} \beta$ fibril formation and accumulation, destabilization of pre-formed $A \beta$ are considered as attractive therapeutic methods for the treatment of Alzheimer's disease., ${ }^{9,10}$ Many animal and clinical studies showed that curcumin as the main constituent of turmeric spice is an effective ingredient in reducing $\mathrm{A} \beta$ plaques in the brain models of Alzheimer's disease. ${ }^{11,12}$ Curcumin is well-known as an anti-inflammation and anti-oxidant ingredient. ${ }^{13}$ It is a lipophilic compound that can easily cross the blood-brain barrier and affect $A \beta$ plaque. ${ }^{13,14}$ It can destabilize the $A \beta$ fibrils and prevent the accumulation of $\mathrm{A} \beta$ polymer. ${ }^{15,16}$ Many animal studies indicated that curcumin could alter $\mathrm{A} \beta$ metabolism in Alzheimer animal models and improve cognition and spatial memory. ${ }^{17-19}$ But in clinical studies there is controversial results about its effects on $A \beta$ clearance and metabolism. ${ }^{20,21}$ For this purpose, we aimed to review the studies which have been done in this area on the effects of curcumin on $A \beta 1-40$ plasma level in clinical studies to find how curcumin affects $A \beta$ metabolism.

\section{Methods}

\section{Search Strategy}

We performed a systematic review and meta-analysis on three randomized clinical trial (RCTs) and one pilot study that assessed the effect of curcumin on $A \beta$ plasma level in Alzheimer's disease. For this purpose, we searched PubMed and Scopus databases up to December 2020, using the following search terms: (curcumin OR diferuloylmethane OR curcuminoids OR turmeric OR "Indian saffron") AND ("Alzheimer disease" OR "Alzheimer's disease" OR "Alzheimer Syndrome" OR "Senile Dementia") AND (amyloid OR "Beta amyloid" OR A $\beta$ ) AND (Intervention OR "controlled trial” OR randomized OR random OR randomly OR placebo OR "clinical trial" OR trial OR "randomized controlled trial" 
OR "randomized clinical trial"). There was no restriction for time or published language. In addition, the reference list of similar articles were screened to avoid missing any data. Duplicate articles were removed from the reference list after searching.

\section{Inclusion Criteria}

Studies with the following characteristics were included in the study: (1) Studies investigating the effects of curcumin on A $\beta$ plasma level in Alzheimer's disease or aged people with dementia, (2) Studies that reported mean \pm SD for $A \beta$, or any other effect sizes from which the calculation of mean \pm SD was possible, (3) Only studies that had placebo and intervention groups were selected and the only difference between the two groups was curcumin regime.

\section{Exclusion Criteria}

In this meta-analysis, we did not enter letter-to-theeditors, comments, short communications, reviews, meta-analyses and animal studies. In our initial search we found 408 articles in PubMed and Scopus. 64 studies were removed because of duplication. In addition, from 344 articles, 337 studies were removed from our study after screening the full text. Only three studies were eligible to enter our study (Figure 1).

\section{Data Extraction}

Data were collected in Excel and included the author's name, year of publication, place of $A \beta$ measurement, number, sex and mean age of the participant in each group, sample size, duration of treatment with curcumin or placebo, study design, dosage of curcumin, methods of measuring outcomes and finally mean \pm SD changes of the desired variables. Data were double checked after extraction. Our A $\beta$ data were converted to $\mathrm{pg} / \mathrm{mL}$. Finally, in studies that reported data in graphical figures, data were extracted using GetData Graph Digitizer 2.24 from figures. ${ }^{22}$ Summary of our data is shown in Table 1.

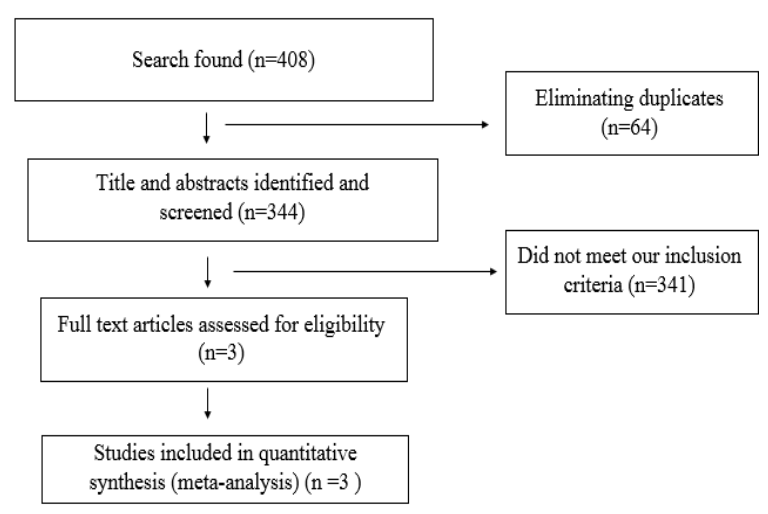

Figure 1. Flow Diagram of Study Selection.

\section{Quality Assessment}

Each study was assessed for quality assessment of risk of bias based on the Cochrane risk of bias assessment tool. ${ }^{23}$ The quality of each of study was screened by two reviewers for the following items: (1) Random sequence generation, (2) Allocation concealment, 93) Selective reporting, (4) Blinding of participants and personnel, 95) Incomplete outcome data, (6) Other sources of bias. Based on the Cochrane handbook, the methods of the studies were ranked as low (L), or high risk of bias $(\mathrm{H})$ or unclear (U) for each field of bias assessment (Table 2).

\section{Statistical Analysis}

Mean change of A $\beta$ 1-40 plasma level was used to calculate effect size. Statistical analysis was performed by STATA, version 13.0 (Stata Corp LP, College Station, TX, USA). We used random effect model for inverse variance. To determine heterogeneity, we used Inconsistency $\left(\mathrm{I}^{2}\right)$. $\mathrm{I}^{2}$ $>50 \%$ was significant for heterogeneity. The estimates of effect sizes were expressed as weighted mean difference (WMD) and 95\% confidence interval (CI).

\section{Results}

\section{Systematic Review Findings}

The summery of the characteristics of the three RCTs included in the current systematic review and metaanalysis are illustrated in Table 1 . The studies were performed in 2008 and 2012. In total 213 participants were analyzed in these studies. The sample size of studies ranged from 8 to 19 participants. Two studies were from the United States ${ }^{24,25}$ and one study from Hong Kong. ${ }^{20}$ Two studies had a randomized parallel clinical trial design $^{24,25}$ and one was pilot study. ${ }^{20}$ All studies included both sexes. In all studies there were control or placebo group and intervention group. In one study curcumin was administrated to healthy elderly ${ }^{25}$ and in the other two participants had Alzheimer's disease, confirmed by clinical symptoms.

In Ringman and colleagues' study in $2012^{24}$ and in Baum and colleagues' study in $2008,{ }^{20}$ different curcumin dosage and duration of regime was used; so each regime was considered as an independent study. The dosage of curcumin varied from $80 \mathrm{mg} / \mathrm{d}$ to $4 \mathrm{~g} / \mathrm{d}$ and the duration of intervention ranged from four weeks to 6 months. Mean (SD) age of the participants ranged from 47 (5) to 77.8 (7.7) years. No study had a high-quality based on Cochrane risk of bias assessment tool. One study has a moderate quality which in which one or more domains had an unclear risk of bias. ${ }^{24}$ The other two studies had a low quality since they had a high risk of bias for three or more domains (Table 2). In Ringman and colleagues' study, ${ }^{24}$ after 24 weeks of treatment with curcumin, $A \beta$ level decreased in both placebo and Alzheimer groups for both doses of $2 \mathrm{~g} / \mathrm{d}$ and $4 \mathrm{~g} / \mathrm{d}$. Also in DiSilvestro and colleagues' study ${ }^{25}$ on healthy elderly, $\mathrm{A} \beta$ plasma level in the placebo group did not change after four weeks but in 
Table 1. General Characteristics of the Included Studies: Randomized Parallel Clinical Trials (R/P)

\begin{tabular}{|c|c|c|c|c|c|c|c|c|c|c|}
\hline $\begin{array}{l}\text { Author/ } \\
\text { Published Year }\end{array}$ & $\begin{array}{c}\text { No. of } \\
\text { Intervention } \\
\text { Group }\end{array}$ & $\begin{array}{l}\text { No. of } \\
\text { Control } \\
\text { Group }\end{array}$ & $\begin{array}{l}\text { Study } \\
\text { Design }\end{array}$ & Country & $\begin{array}{l}\text { Gender of } \\
\text { Participants }\end{array}$ & $\begin{array}{c}\text { Age of } \\
\text { Participants in } \\
\text { Intervention } \\
\text { Group }\end{array}$ & $\begin{array}{c}\text { Age of } \\
\text { Participants in } \\
\text { Control } \\
\text { Group }\end{array}$ & $\begin{array}{l}\text { Dose of } \\
\text { Curcumin }\end{array}$ & $\begin{array}{l}\text { Duration of } \\
\text { Regime }\end{array}$ & $\begin{array}{l}\text { Health } \\
\text { Condition }\end{array}$ \\
\hline $\begin{array}{l}\text { Ringman et al/ } \\
2012\end{array}$ & 9 & 11 & $\mathrm{R} / \mathrm{P}$ & USA & Both & $76.7 \pm 5.6$ & $70.2 \pm 12.4$ & $2 \mathrm{~g} / \mathrm{d}$ & 24 weeks & Alzheimer \\
\hline $\begin{array}{l}\text { Ringman et } \\
\mathrm{al} / 2012\end{array}$ & 10 & 11 & $\mathrm{R} / \mathrm{P}$ & USA & Both & $75.3 \pm 6.9$ & $70.2 \pm 12.4$ & $4 \mathrm{~g} / \mathrm{d}$ & 24 weeks & Alzheimer \\
\hline $\begin{array}{l}\text { DiSilvestro et } \\
\mathrm{al} / 2012\end{array}$ & 19 & 19 & $\mathrm{R} / \mathrm{P}$ & USA & Both & $47 \pm 5$ & $48 \pm 6$ & $80 \mathrm{mg} / \mathrm{d}$ & 4 weeks & Healthy \\
\hline $\begin{array}{l}\text { Baum et } \\
\text { al/2008 }\end{array}$ & 11 & 8 & Pilot study & Hong Kong & Both & $73.4 \pm 6.6$ & $77.8 \pm 7.7$ & $4 \mathrm{~g} / \mathrm{d}$ & 6 months & Alzheimer \\
\hline $\begin{array}{l}\text { Baum et } \\
\mathrm{al} / 2008\end{array}$ & 8 & 8 & Pilot study & Hong Kong & Both & $69 \pm 10.9$ & $77.8 \pm 7.7$ & $1 \mathrm{~g} / \mathrm{d}$ & 1 month & Alzheimer \\
\hline
\end{tabular}

Table 2. Assessment of Risk of Bias of Each Included Study

\begin{tabular}{|c|c|c|c|c|c|c|c|}
\hline Author/ Published Year & $\begin{array}{c}\text { Random Sequence } \\
\text { Generation }\end{array}$ & $\begin{array}{c}\text { Allocation } \\
\text { Concealment }\end{array}$ & $\begin{array}{l}\text { Selective } \\
\text { Reporting }\end{array}$ & $\begin{array}{l}\text { Blinding (Participants } \\
\text { and Personnel) }\end{array}$ & $\begin{array}{l}\text { Blinding (Outcome } \\
\text { Assessment) }\end{array}$ & $\begin{array}{c}\text { Incomplete } \\
\text { Outcome Data }\end{array}$ & $\begin{array}{l}\text { Other Sources } \\
\text { of Bias }\end{array}$ \\
\hline Ringman et al/2012 & $\mathrm{L}$ & $\mathrm{L}$ & $\mathrm{L}$ & $\mathrm{L}$ & Not clear & $\mathrm{L}$ & $\mathrm{L}$ \\
\hline DiSilvestro et al/2012 & $\mathrm{L}$ & $\mathrm{H}$ & $\mathrm{L}$ & $\mathrm{H}$ & Not clear & $\mathrm{L}$ & L \\
\hline Baum et al/2008 & L & L & L & Not clear & Not clear & $\mathrm{H}$ & L \\
\hline
\end{tabular}

$\mathrm{H}$, high risk ; L, low risk

the curcumin group, $A \beta$ level decreased. In Baum and colleagues' study ${ }^{20}$ the $A \beta$ level in intervention groups with different duration of curcumin regime (1 and 6 months) increased significantly after 1 month. In the placebo group, the level of $A \beta$ decreased after 1 month but then after 1 to 6 months, there was no significant change in $A \beta$ levels in both groups.

\section{Meta-analysis Finding}

Overall, three studies with total population of 213 adults were analyzed for the effect of curcumin on $A \beta$ plasma level. Our meta-analysis showed that curcumin had no significant effect on $A \beta$ level in these three studies (WMD: 5.3, 95\% CI: 0.78-9.97). There is no significant heterogeneity between the studies $\left(\mathrm{I}^{2}=6.6 \%, P=0.369\right)$. Also, we did subgroup analysis for healthy conditions and there was no significant change in serum IL-10 levels in in the two methods of measurement (WMD: - $-0.10,95 \%$ CI:-0.44 $-0.24, \mathrm{I}^{2}=0.000 \%, P=0.495$, Figure 2 ).

\section{Discussion}

Curcumin is a low molecular weight molecule and lipophilic compound that can easily cross the bloodbrain barrier. ${ }^{26}$ Curcumin has many proinflammatory effects and able to neutralize many toxicity factors on many organs. Nowadays, curcumin was known as an anti-cancer genic compound. ${ }^{27}$ Recent animal studies also support the hypothesis that curcumin is beneficial for cognitive disorders. ${ }^{28-30}$ Also studies have suggested that dietary curcumin was associated with better cognitive function and lower prevalence of dementia. ${ }^{30,31}$ Another study showed that free curcumin could reduce amyloid plaque burden and insoluble $A \beta$ peptide in the serum, ${ }^{32}$ But in clinical studies there is controversial results about the effects of curcumin on dementia diseases. Our results from meta-analysis showed that there was no significant decrease of $A \beta$ on Alzheimer's disease in overall results of clinical studies. In Ringman and colleagues' study, ${ }^{24}$ the percent of $A \beta$ decrease was not big. It may be the decrease could become larger with a longer intervention. Also in DiSilvestro and colleagues' study ${ }^{25}$ there was no clinical or biochemical evidence of efficacy against Alzheimer's disease and $A \beta$ serum level did not change in the intervention group compared with the placebo group. In Baum and colleagues' study ${ }^{20}$ serum $A \beta-40$ tended to rise in the intervention group; possibly, it may show the ability of curcumin to disaggregate $A \beta$ deposits in the brain, releasing $A \beta$ for circulation and disposal. The variety of severe forms of the disease in patients, duration from onset of the disease, duration of regime and dose of curcumin are important factors that can affect the results. If these factors are equalized between patients, the results will be more reliable. These factors are very important in the final results of the systematic review and metaanalysis.

\section{Conclusion}

Based on available data in our systematic review and meta-analysis, there was no evidence about the effects of curcumin to change the $A \beta-40$ serum level. For further investigation of the effect of curcumin on serum $A \beta$ level, more clinical trials are needed. 


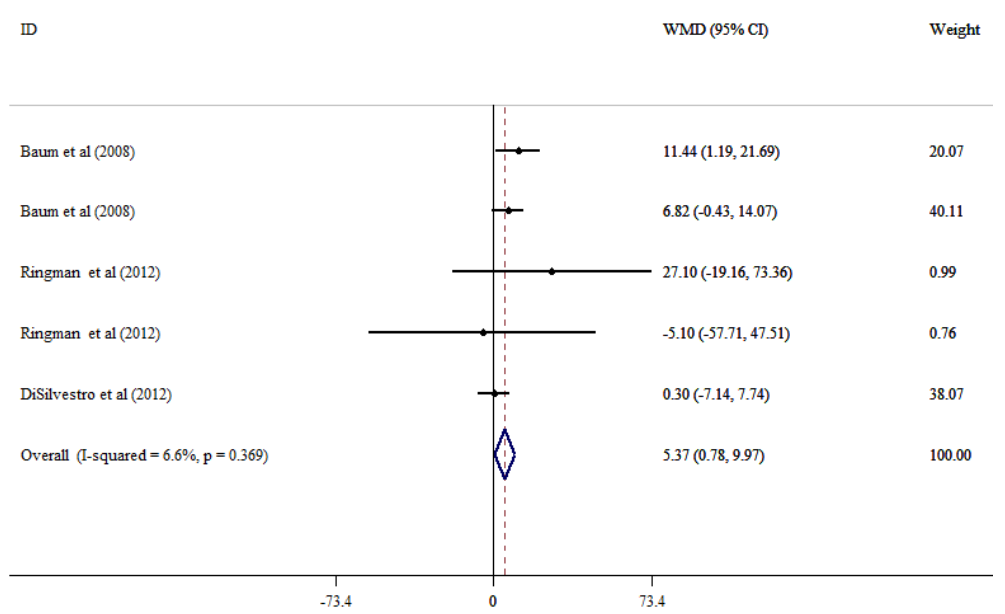

Figure 2. Forest Plots for the Effect of Curcumin on A $\beta$ level in Serum Analysis on Alzheimer's Patient, Expressed as Mean Differences Between Intervention and Control Groups. The area of each square is proportional to the inverse of the variance of the weighted mean difference (WMD). Horizontal lines represent \%95 Cls. Diamonds represent pooled estimates from fixed-effects analysis

\section{Conflict of Interest}

The authors declare that they have no conflict of interests.

\section{Authors' Contribution}

All authors contributed to the conception, design of the study and data acquisition.

\section{Funding/Support}

This study did not receive any grant or funding from any private or academic research center.

\section{Ethical Statement}

Not applicable.

\section{References}

1. Cummings JL, Cole G. Alzheimer disease. JAMA. 2002;287(18):2335-8. doi: 10.1001/jama.287.18.2335.

2. Mehrabadi S, Motevaseli E, Sadr SS, Moradbeygi K. Hypoxicconditioned medium from adipose tissue mesenchymal stem cells improved neuroinflammation through alternation of toll like receptor (TLR) 2 and TLR4 expression in model of Alzheimer's disease rats. Behav Brain Res. 2020;379:112362. doi: 10.1016/j.bbr.2019.112362.

3. Bourassa P, Tremblay C, Schneider JA, Bennett DA, Calon F. Beta-amyloid pathology in human brain microvessel extracts from the parietal cortex: relation with cerebral amyloid angiopathy and Alzheimer's disease. Acta Neuropathol. 2019;137(5):801-23. doi: 10.1007/s00401-019-01967-4.

4. Mehrabadi S, Sadr SS. Administration of vitamin D3 and E supplements reduces neuronal loss and oxidative stress in a model of rats with Alzheimer's disease. Neurol Res. 2020;42(10):862-8. doi: 10.1080/01616412.2020.1787624.

5. Bruckmann S, Brenn A, Grube M, Niedrig K, Holtfreter S, von Bohlen und Halbach $\mathrm{O}$, et al. Lack of P-glycoprotein results in impairment of removal of beta-amyloid and increased intraparenchymal cerebral amyloid angiopathy after active immunization in a transgenic mouse model of Alzheimer's disease. Curr Alzheimer Res. 2017;14(6):656-67. doi: 10.21 74/1567205013666161201201227.

6. Mehrabadi S, Sadr SS. Assessment of probiotics mixture on memory function, inflammation markers, and oxidative stress in an Alzheimer's disease model of rats. Iran Biomed J. 2020;24(4):220-8. doi: 10.29252/ibj.24.4.220.

7. Hemonnot AL, Hua J, Ulmann L, Hirbec H. Microglia in Alzheimer disease: well-known targets and new opportunities. Front Aging Neurosci. 2019;11:233. doi: 10.3389/fnagi.2019.00233.

8. Prokop S, Lee VMY, Trojanowski JQ. Neuroimmune interactions in Alzheimer's disease-New frontier with old challenges? Prog Mol Biol Transl Sci. 2019;168:183-201. doi: 10.1016/bs.pmbts.2019.10.002.

9. Panza F, Lozupone $M$, Logroscino G, Imbimbo BP. A critical appraisal of amyloid- $\beta$-targeting therapies for Alzheimer disease. Nat Rev Neurol. 2019;15(2):73-88. doi: 10.1038/s41582-018-0116-6.

10. Chen XQ, Mobley WC. Alzheimer disease pathogenesis: insights from molecular and cellular biology studies of oligomeric $A \beta$ and tau species. Front Neurosci. 2019;13:659. doi: 10.3389/fnins.2019.00659.

11. Farkhondeh T, Samarghandian S, Pourbagher-Shahri AM, Sedaghat $M$. The impact of curcumin and its modified formulations on Alzheimer's disease. J Cell Physiol. 2019;234(10):16953-65. doi: 10.1002/jcp.28411.

12. Mukhopadhyay CD, Ruidas B, Chaudhury S. Role of curcumin in treatment of Alzheimer disease. Int J Neurorehabilitation. 2017;4(3):274. doi:10.4172/2376-0281.1000274

13. Farooqui AA. Therapeutic Potentials of Curcumin for Alzheimer Disease. Cham: Springer; 2016.

14. Tang M, Taghibiglou C. The mechanisms of action of curcumin in Alzheimer's disease. J Alzheimers Dis. 2017;58(4):100316. doi: 10.3233/jad-170188.

15. Forouzanfar F, Read MI, Barreto GE, Sahebkar A. Neuroprotective effects of curcumin through autophagy modulation. IUBMB Life. 2020;72(4):652-64. doi: 10.1002/ iub.2209.

16. Veldman ER, Jia Z, Halldin C, Svedberg MM. Amyloid binding properties of curcumin analogues in Alzheimer's disease postmortem brain tissue. Neurosci Lett. 2016;630:183-8. doi: 10.1016/j.neulet.2016.07.045.

17. Bicer N, Yildiz E, Yegani AA, Aksu F. Synthesis of curcumin complexes with iron(iii) and manganese(ii), and effects of curcumin-iron(iii) on Alzheimer's disease. New J Chem. 
2018;42(10):8098-104. doi: 10.1039/c7nj04223j.

18. Reddy PH, Manczak M, Yin X, Grady MC, Mitchell A, Tonk S, et al. Protective effects of Indian spice curcumin against amyloid- $\beta$ in Alzheimer's disease. J Alzheimers Dis. 2018;61(3):843-66. doi: 10.3233/jad-170512.

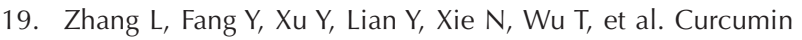
improves amyloid $\beta$-peptide (1-42) induced spatial memory deficits through BDNF-ERK signaling pathway. PLoS One. 2015;10(6):e0131525. doi: 10.1371/journal.pone.0131525.

20. Baum L, Lam CW, Cheung SK, Kwok T, Lui V, Tsoh J, et al. Sixmonth randomized, placebo-controlled, double-blind, pilot clinical trial of curcumin in patients with Alzheimer disease. J Clin Psychopharmacol. 2008;28(1):110-3. doi: 10.1097/ jcp.0b013e318160862c.

21. Rainey-Smith SR, Brown BM, Sohrabi HR, Shah T, Goozee KG, Gupta VB, et al. Curcumin and cognition: a randomised, placebo-controlled, double-blind study of communitydwelling older adults. Br J Nutr. 2016;115(12):2106-13. doi: 10.1017/s0007114516001203.

22. Fedorov S: GetData Graph Digitizer version 2.24. Available from: http://getdata-graph-digitizer.com/.

23. Higgins J, Thomas J. Cochrane Handbook for Systematic Reviews of Interventions. Cochrane; 2011.

24. Ringman JM, Frautschy SA, Teng E, Begum AN, Bardens J, Beigi $M$, et al. Oral curcumin for Alzheimer's disease: tolerability and efficacy in a 24-week randomized, double blind, placebo-controlled study. Alzheimers Res Ther. 2012;4(5):43. doi: 10.1186/alzrt146.

25. DiSilvestro RA, Joseph E, Zhao S, Bomser J. Diverse effects of a low dose supplement of lipidated curcumin in healthy middle aged people. Nutr J. 2012;11:79. doi: 10.1186/14752891-11-79.

26. Porro C, Cianciulli A, Trotta T, Lofrumento DD, Panaro MA. Curcumin regulates anti-inflammatory responses by JAK/
STAT/SOCS signaling pathway in BV-2 microglial cells. Biology (Basel). 2019;8(3):51. doi: 10.3390/biology8030051.

27. Potter PE. Curcumin: a natural substance with potential efficacy in Alzheimer's disease. J Exp Pharmacol. 2013;5:2331. doi: 10.2147/jep.s26803.

28. He W, Yuan K, Ji B, Han Y, Li J. Protective effects of curcumin against neuroinflammation induced by $A \beta 25-35$ in primary rat microglia: modulation of high-mobility group box 1 , toll-like receptor 4 and receptor for advanced glycation end products expression. Ann Transl Med. 2020;8(4):88. doi: 10.21037/ atm.2019.12.147.

29. Huang N, Lu S, Liu XG, Zhu J, Wang YJ, Liu RT. PLGA nanoparticles modified with a BBB-penetrating peptide COdelivering $A \beta$ generation inhibitor and curcumin attenuate memory deficits and neuropathology in Alzheimer's disease mice. Oncotarget. 2017;8(46):81001-13. doi: 10.18632/ oncotarget.20944.

30. Liu Z, Jiang Y, Wang Y, Gao H, Chen Z, Fang L. Curcumin improves learning and memory ability via inhibiting activated microglia-mediated inflammation in mouse models of Alzheimer's disease. Int J Clin Exp Med. 2018;11(11):1220410.

31. Sundaram JR, Poore CP, Sulaimee NHB, Pareek T, Cheong WF, Wenk MR, et al. Curcumin ameliorates neuroinflammation, neurodegeneration, and memory deficits in p25 transgenic mouse model that bears hallmarks of Alzheimer's Disease. J Alzheimers Dis. 2017;60(4):1429-42. doi: 10.3233/jad170093.

32. Shytle RD, Tan J, Bickford PC, Rezai-Zadeh K, Hou L, Zeng $\mathrm{J}$, et al. Optimized turmeric extract reduces $\beta$-amyloid and phosphorylated Tau protein burden in Alzheimer's transgenic mice. Curr Alzheimer Res. 2012;9(4):500-6. doi: 10.2174/156720512800492459. 